\title{
A Long-term Strategy for Energy and Cost Performance Improvement of Existing Residential Buildings: Step-by-step Renovation in Turkey
}

\author{
Touraj Ashrafian 1,*, Zerrin Yllmaz ${ }^{2}$, and Nazanin Moazzen ${ }^{3}$ \\ ${ }^{1}$ Faculty of Architecture and Design, Özyeğin University, Istanbul, Turkey \\ ${ }^{2}$ Faculty of Architecture, Istanbul Technical University, Istanbul, Turkey \\ ${ }^{3}$ Faculty of Architecture and Design, Maltepe University, Istanbul, Turkey
}

\begin{abstract}
Recast version of Energy Performance of Building Directive (EPBD-Recast) obligate member states to keep the cost analysis in parallel with the energy analysis during the renovation actions for the existing building by taking the cost-optimal level of minimum energy performance requirement to the account. Although this cost-optimal level is indicating the minimum cost level for a period, it can provide buildings' owners with an enormous initial cost. One of the most challenging barriers to energy efficient and cost-optimal renovation of existing buildings is the reluctance of owners to involve in their project as an investor due to the high cost of application. Particularly in developing countries, such reluctance is more tangible as the governments are not capable of providing enough financial incentives for owners due to a large number of buildings that should be renovated and small available budget. A proper solution for the problem is to divide necessary actions for each building to certain sub-actions and apply them as a step-by-step renovation project. On the other hand, the progressive application of renovation activities has some restrictions. It is necessary to define the due amount for households and keep the cost of each step within the payable range.

Moreover, the low rate of building renovation which affects the EU goals can be improved remarkably by application of step-by-step actions not only by increasing the number of owners' contributions but also by improving the time of implementation, proper distribution of skilled labours and directed economic resources. This paper aims to assess the step-by-step application of the energy efficient renovation actions through energy and cost analysis under Turkey's climatic, economic and sociological conditions. One of 26 reference residential buildings in Turkey is analysed in this paper. The due amount for each step is defined, and some renovation actions and their combinations applied to the case building and the results compared with the base condition. Then a proper combination of measures established based on the cost-optimal analyses. These appropriately combined actions are then divided into some sub-actions; following this, cost and energy studies are conducted again to determine the appropriate arrangement of sub-actions.
\end{abstract}

\section{Introduction}

Residential buildings which are responsible for about $27 \%$ of overall energy consumption and approximately $68 \%$ of energy consumption in building stock, cover approximately $75 \%$ of the whole building area in EU [1]. It is estimated that three-quarters of the housing stock to be found in 2050 already exists [2], and currently, about $35 \%$ of buildings are over 50 years old [3]. In Turkey, the construction sector's total energy consumption of total energy-related emissions of $\mathrm{CO}_{2}$ emissions from the construction sector constitutes about 35\% and 32\%. According to 2008 statistics, there are 18.4 million households in Turkey where housing consumes $36 \%$ of the total energy. It is expected to save about $\$ 10$ billion a year by merely applying the proper insulation [4]. By these facts, it is obvious that the energy efficiency of the existing residential building stock is unavoidable and totally beneficial. There is considerable potential for energy efficiency improvement through an in-depth renewal of buildings and reduced energy consumption through low-cost measures. Even modest changes in energy performance and in the way we operate a building can have a significant impact on lowering total energy consumption and cost. Although financing of renewal activities is a substantial obstacle in this area, the development of minimum investment cost and maximum annual return on investment and applicable methods can encourage the owners to participate in activities. It will trigger the renovation market and bring 
significant benefits to societies. Renovation measures can include low, medium and high initial investment costs. Each measure has a unique effect on many buildings are going to be renovated. The gradual renewal, which results not only in low investment cost measures but also in low annual payments, even at moderate and high investment costs, can increase the number of renovation projects and can trigger the market by encouraging owner participation. What is crucial in the step-by-step actions is that the allocation of the processes to a different period must be investigated thoroughly and every aspect should be placed under scrutiny to avoid any adverse or lock-in effect.

Recast version of Energy Performance of Building Directive (EPBD-Recast) [5] introduced the cost-optimal level as an energy performance level in which leads to the lowermost cost during the projected economic lifecycle. EU's Energy Efficiency Directive (EED), Directive 2012/27/EU [6], obligates member states to renew existing building stock taking cost-effective actions. Also, M.S. had to form a long-term strategy for organizing investment in the renewal of domestic building stock. Such a plan should include a depiction of cost-effective approaches to amendments by construction type and climate zone. The plan should address profound low-cost developments that have led to a modification, ensuring that a building is both delivered and achieves a precise high energy performance by significantly reducing the final energy consumption compared to levels before the renovation. Besides, existing obstacles to refurbish of present building stock on the basis of incentives between diverse actors should also be addressed at the nationalised level. The strategy should also include deep progressive modifications. Not only the low initial investment cost but also the gradual renewal with moderate and high investment cost can increase the quantity of renovation projects in communities. The appropriate distribution of renewal activities over a different period is the most crucial step of the progressive renewal process. It is also important to align the proper steps due to improper thermal bridge behaviour of the components to prevent the unpredictable "lock-in" effect. Progressive execution can satisfy the owners for inclusion in the renovation project. A report by the European Commission [7] shows how funding for energy efficiency in buildings has to be improved. The latest European amending directive of buildings' energy performance and energy efficiency directives, 2018/844/EU, continues to undertake longterm renewal strategies, including gradual deep renovations for building stocks, and forces all member states to support the renewal of both public and nonresidential buildings, and energy efficiency up to 2050 a high and decarbonized building stock [8]. Amending directive of EPBD-recast [9] ask member states to indicate their short-term (2030), mid-term (2040) and long-term (2050) objectives and state the estimated output of their long-term renovation approaches.

Compatible with EU, there are continuing and accomplished actions of energy efficiency renovation in Turkey. The Energy Efficiency Law was recognised in
2007. Through Building Energy Performance of Turkey (Bep-TR) regulation, the base for building certification procedure is provided, and a national calculation process of building energy performance is developed [10]. Reference buildings for cost-optimality evaluation are established through a project supported by the Scientific and Technological Research Council of Turkey (TÜBİTAK). In the study, cost-optimal analyses conducted for some of those reference buildings [11].

\section{Methodology}

The methodology of the study is based on the method described in EPBD-Recast 2010 [2] and adapted from Ashrafian et al. [12]. The precise methodology for the study has five main phases, starts from base building determination and ends by determining the scenarios for step-by-step renovation. In general, the method involves the following steps:

Step 1: Determine the base building and their physical, thermo-physical properties and energy systems as well as the operational profile,

Step 2: Determining the energy performance of the buildings using primary energy consumption,

Step 3: Determining improvement measures,

Step 4: Conduct energy cost analyses to strengthen the measurements and identify the optimal measures to save and the amount of the costs borne by the owners. While the energy analysis includes the determination of primary energy consumption (PEC) and $\mathrm{CO}_{2}$ emissions, the economic evaluation strength the measures include the initial investment cost and the calculation of the overall cost for the calculation period. The step consists of the determination of the payback period and the optimal cost level for the retrofit measures,

Step 5: Investigation on step by step to define a proper sequence for steps if the cost of the investment is higher than the reasonable amount, identify the appropriate progressive scenarios and perform an energy cost analysis. (Figure 1)

Accordingly, the reference building should be defined, and then related analyses should be conducted. Two distinctive analyses should be done; the first one is energy analysis, and the next one is cost analysis. In the study, the energy analysis is done using detailed dynamic computational software, Energyplus. The cost analysis is done based on the calculation method described in EN 15459 [13].

The methodology described in EN 13465 [14] is used to calculate building infiltration rate. The primary energy conversion values based on the Turkish Ministry of Environment and Urbanization announcement are 2.36 for electricity while it is 1 for another type of fuels. The lifespan of the architectural enhancements assumed to be 40 years while it is supposed to be between 15 and 20 years for HVAC and lighting improvements.

The approach is firstly applied to a building located in Antalya, a city with hot-humid climate and the results are presented in the paper. Then the same approach is applied to the same building located in Istanbul and Erzurum which are located in temperate-humid and cold 
climate of Turkey respectively. Just the final and cumulative results for these situations are presented as well.

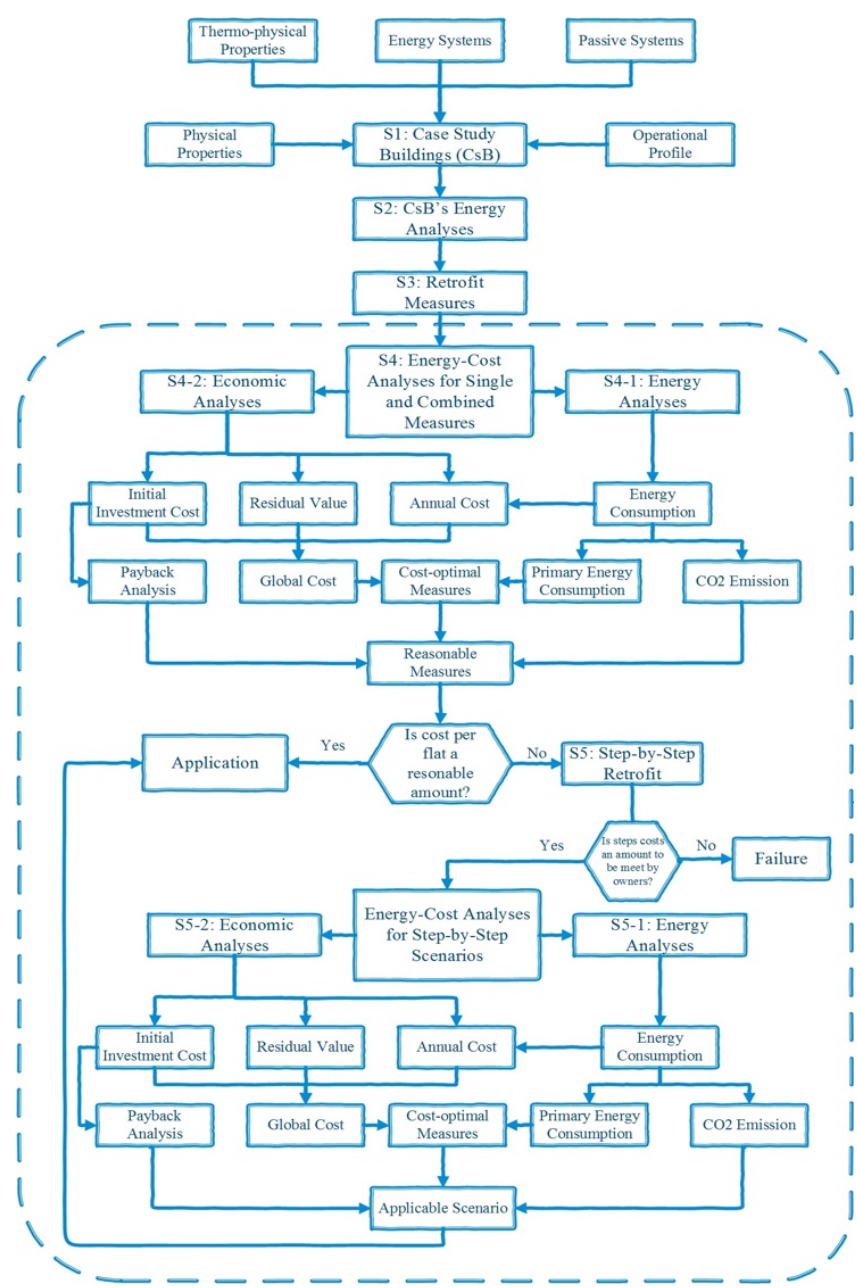

Fig. 1. The methodology scheme for progressive renovation.

\section{Reference building and its properties}

As stated in the introduction, to determine the residential reference building in Turkey, a study supported by the Scientific and Technological Research Council of Turkey, TUBITAK, can be referred [11]. 25 buildings belongs to 3 different construction intervals (Single Family Houses, Apartments and High-Rise Luxury Houses) in three broad categories have been defined as reference residential buildings through that study. One of them was chosen as the reference building in the current research which is a row apartment. The building is assumed to be in Antalya, in hot and humid climates.

The reference building was built between 2000-2008 containing five floors with 3 meter height and a flat roof. Two separated units are available on each floor, and each of them has three bedrooms and a living room. Majority of living spaces are in the South direction. Figure 2 illustrates the plan drawings and $3 \mathrm{D}$ views of the case building.
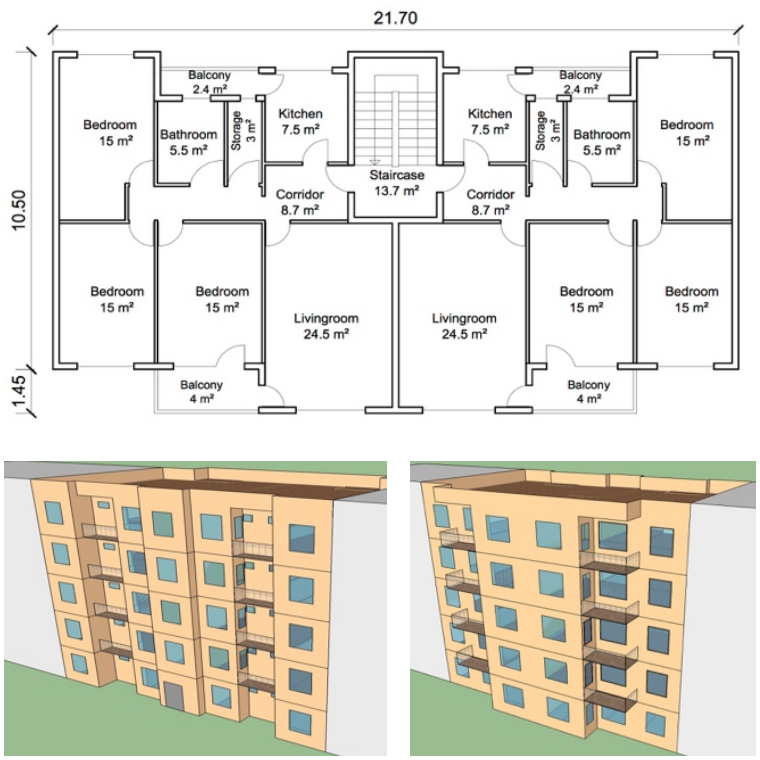

Figure 2: Plan drawing and 3D views of the reference building.

The architectural components' U-values are picked from TS825-2000 standard. Glazing systems' U-value sets to $2.8 \mathrm{~W} / \mathrm{m}^{2} . \mathrm{K}$. As there is insufficient information associated with SHGC in that standard, hence, it is obtained from the recent version of that standard, TS825-2013 [15]. Table 1 indicates the U-value of opaque and glazing components of the reference building.

Table 1: U-values $\left[\mathrm{W} / \mathrm{m}^{2} . \mathrm{K}\right]$ of the opaque and glazing components.

\begin{tabular}{|c|c|c|c|c|}
\hline & $\begin{array}{c}\text { Exterior } \\
\text { Wall }\end{array}$ & Roof & $\begin{array}{c}\text { Ground } \\
\text { Floor }\end{array}$ & Glazing \\
\hline Existing Building & 0.8 & 0.5 & 0.8 & 2.8 \\
\hline
\end{tabular}

The building heating system is an individual system supporting by a combi-boiler, with 0.75 "Nominal Thermal Efficiency", the distributors are baseboard hot water convectors. Also, it is providing domestic hot water (DHW). The cooling system is an individual Packaged air-conditioner units (PACU) with 2.6 COP efficiency that are installed in each unit to cool indoors. The natural ventilation is providing fresh air when it is necessary. Based on Building Energy Performance of Turkey (Bep-Tr) regulation, 0.5 ACH is used for the infiltration rate. The setpoint temperatures for cooling and heating are defined Based on values provided by Bep-Tr. Interior lighting set based on Bep-Tr and international standards such as CIBSE Code for Lighting. Based on Bep-Tr, to provide the necessary illumination level, $70 \%$ of artificial light is provided by $36 \mathrm{~W}$ and 3250 Lumen fluorescent lamps while $75 \mathrm{~W}$ and 930 Lumen incandescent lamps provide the rest. The illumination level is chosen from EN standards.

\subsection{Determination of the Renovation Measures}

A sequence of scenarios was developed to use in the architectural, mechanical and lighting systems of the building to define suitable and applicable renovation 
measure. Based on Ashrafian et al. [12] the architectural measures are organized and the TS825-2013 standard, that is the latest version of the related standard for Turkish buildings, delivers the base for architectural enhancements. HVAC and lighting measures are decided based on consultancy with market experts. Foremost, the individual measures were applied, and then combinations of the actions were developed. The combination is being implemented on the base building to identify reasonable solutions from cost and energy consumption points of view. Table 2 is illustrating the individual renovation measures considered in the study.

Table 2: Statements of individual renovation actions.

\begin{tabular}{|c|c|}
\hline Acr. & Single Measure \\
\hline S1 & $\begin{array}{l}25 \% \text { higher wall insulation compared to the } \\
\text { requirements of TS825-2013; }\end{array}$ \\
\hline $\mathbf{S 2}$ & $\begin{array}{l}50 \% \text { higher wall insulation compared to the } \\
\text { requirements of TS825-2013; }\end{array}$ \\
\hline S3 & $\begin{array}{l}25 \% \text { higher insulation of whole opaque systems } \\
\text { compared to the requirements of TS } 825-2013 ;\end{array}$ \\
\hline S4 & $\begin{array}{l}50 \% \text { higher insulation of whole opaque systems } \\
\text { compared to the requirements of TS } 825-2013 \text {; }\end{array}$ \\
\hline $\mathbf{S 5}$ & $\begin{array}{l}\text { 1st Glass upgrade: } \mathrm{U}=1.8 \mathrm{~W} / \mathrm{m}^{2} . \mathrm{K}(\mathrm{TS} 825-2013 \\
\text { requirement), Tvis }=0.79, \mathrm{SHGC}=0.56 ;\end{array}$ \\
\hline S6 & $\begin{array}{l}\text { 2nd Glass upgrade: } \mathrm{U}=1.6 \mathrm{~W} / \mathrm{m}^{2} . \mathrm{K} \text {, Tvis }=0.79 \text {, } \\
\text { SHGC }=0.56 \text {; }\end{array}$ \\
\hline S7 & $\begin{array}{l}\text { 3rd Glass upgrade: } \mathrm{U}=1.6 \mathrm{~W} / \mathrm{m}^{2} . \mathrm{K}, \text { Tvis }=0.71 \text {, } \\
\mathrm{SHGC}=0.44 \text {; }\end{array}$ \\
\hline S8 & $\begin{array}{l}\text { 4th Glass upgrade: } \mathrm{U}=1.3 \mathrm{~W} / \mathrm{m}^{2} . \mathrm{K} \text {, Tvis }=0.71 \text {, } \\
\text { SHGC }=0.44 ;\end{array}$ \\
\hline S9 & $\begin{array}{l}\text { 5th Glass upgrade: } \mathrm{U}=1.1 \mathrm{~W} / \mathrm{m}^{2} . \mathrm{K} \text {, Tvis }=0.71 \text {, } \\
\text { SHGC }=0.44 ;\end{array}$ \\
\hline S10 & $\begin{array}{l}\text { 6th Glass upgrade: } \mathrm{U}=0.9 \mathrm{~W} / \mathrm{m}^{2} . \mathrm{K} \text {, Tvis }=0.69 \text {, } \\
\text { SHGC }=0.48 \text {; }\end{array}$ \\
\hline S11 & $\begin{array}{l}\text { 7th Glass upgrade: } \mathrm{U}=0.9 \mathrm{~W} / \mathrm{m}^{2} . \mathrm{K} \text {, Tvis }=0.63 \text {, } \\
\text { SHGC }=0.39 ;\end{array}$ \\
\hline S12 & Shading component (External Blind) constructions; \\
\hline S13 & $\begin{array}{l}\text { Shading component (Exterior Drop Curtain) } \\
\text { constructions; }\end{array}$ \\
\hline S14 & $\begin{array}{l}\text { Replacement of current heat pumps by variable flow } \\
\text { pumps; }\end{array}$ \\
\hline S15 & Integration of solar collectors to the heating system; \\
\hline S16 & $\begin{array}{l}\text { Renewal of radiator system with heated floor } \\
\text { system; }\end{array}$ \\
\hline S17 & $\begin{array}{l}\text { Renewal of current combi-boilers with condensing } \\
\text { combi-boilers; }\end{array}$ \\
\hline S18 & $\begin{array}{l}\text { Renewal of current individual combi-boilers with the } \\
\text { central condensing system; }\end{array}$ \\
\hline S19 & $\begin{array}{l}\text { Renewal of current individual combi-boilers with the } \\
\text { central non-condensing system; }\end{array}$ \\
\hline S20 & $\begin{array}{l}\text { Renewal of existing PACUs with highly efficient } \\
\text { one with } 3.5 \text { COP; }\end{array}$ \\
\hline S21 & $\begin{array}{l}\text { Renewal of current PACUs with highly efficient one } \\
\text { with } 4.0 \mathrm{COP} \text {; }\end{array}$ \\
\hline S22 & Application of Photovoltaic system; \\
\hline $\mathbf{S 2 3}$ & Replacements of CFL lamps with LED lamps. \\
\hline
\end{tabular}

\subsection{Cost Calculation}

To calculate the cost of different measures based on the net present value method, inflation and interest rates are set to $6 \%$ and $4 \%$ respectively. Total calculation period is set to 30 years as EPBD-Recast obligates it for residential buildings. Electricity and natural gas costs are calculated according to the local distributors' announced costs. To estimate the initial investment cost, market analysis is done for materials and components. Then the cost provided by three different dealers of various factories utilised to define the average price.

Cost per apartment can be calculated by dividing the investment cost by the total units presented in building. A literature review is conducted to estimate the acceptable amount of expenditure. Turkey Statistical Institute (TSI), according to the median income of households with annual income in Turkey in 2013 was realised at $22752 \mathrm{TL}$. By implementing $8.8 \%$ of the inflation rate, the median income family should be 29302 TL, in average earnings by 2016. Generally, 25\% of household spending in Turkey belong to the residential lease and maintenance. If a landlord consumes all of his annual income, approximately 7325 TL is spent for housing. According to the Ministry of Energy and Natural Resources of Turkey, generally, the household pays about 73 and 135 TL per month for natural gas and electricity. It means that the total annual home bill for families is 2496 TL. An entity may invest in accommodation expenses of a family of TL 4829 for renovations. For a low-income group, this amount is approximately $2310 \mathrm{TL}$. Therefore, it is supposed that each apartment owner can invest around $2310 \mathrm{TL}$ per year for renewal action and that the analysis is a reasonable amount. Measures that are higher than the acceptable price and are lower than $4620 \mathrm{TL}$ per apartment should be divided into steps at reasonable rates or implemented with the one-year postponement. Measures exceeding 4620 TL per unit should be excluded from further analysis. In this study, two different scenarios will be examined; however, other situations can be studied with a similar method. While the steps of the first scenario are based on cost per circle, the levels of the second scenario are based on the primary energy savings of each measure. The initial scenario starts with actions that provide the lowest cost per apartment. The second scenario begins with the action that delivers the maximum primary energy savings.

To determine the average PEC of the building under progressive renovation scenarios, it is necessary to perform detailed simulations distinctly for every single measure by using the earlier steps enhancements. For instance, to estimate the PEC of the second phase, the enhancements in the first stage should be implemented as well. After accomplishing all essential calculations, the initial results should be multiplied by the duration of every step (the interval of years that the next phase will be applied) and divided by calculation period. The final step length is the total calculation period minus the last stage's implementation year. Consequently, the following formulation should be used to estimate the mean PEC for total calculation period: (Eq. 1)

$P E C=((P E C 1 \times d 1)+\cdots+(P E C(n-1) \times d(n-1))+(P E C n \times(\tau-$
$(d 1+d 1+\cdots+d(n-1))))) / \tau$ 


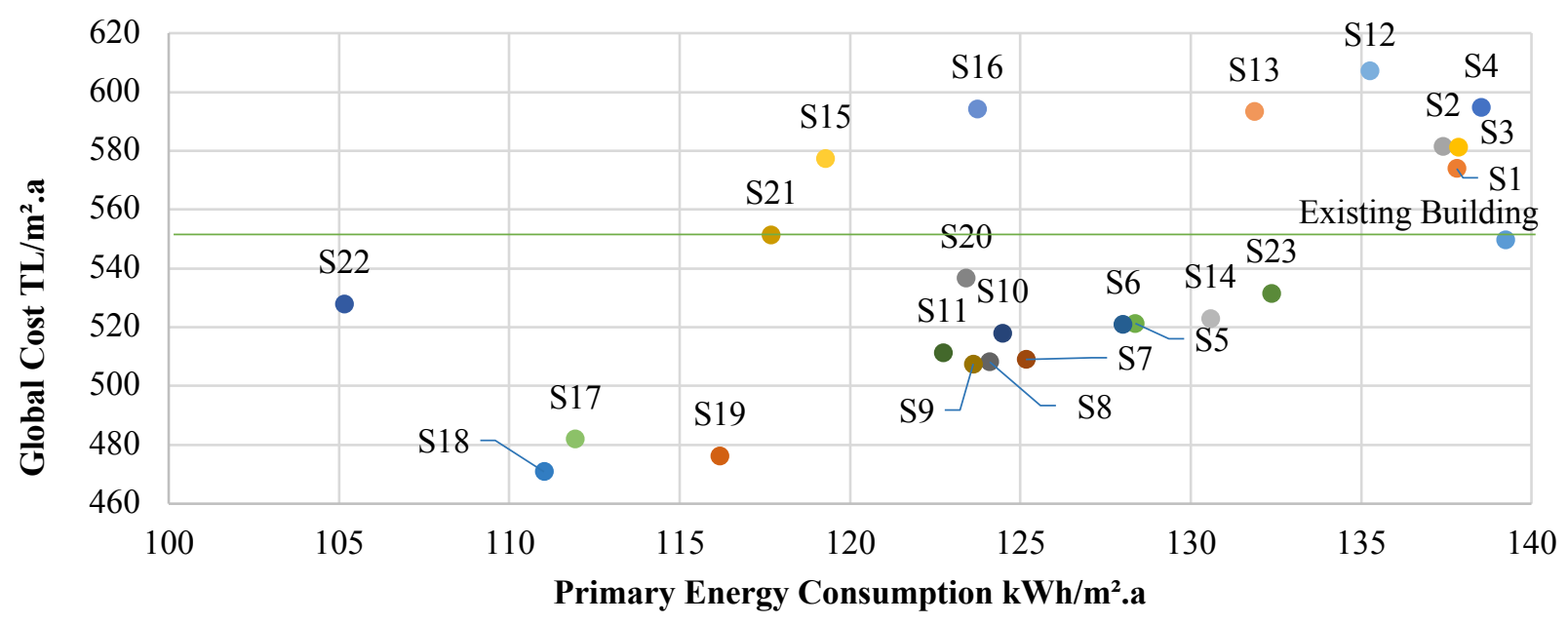

Fig. 4. The GC vs PEC graph for individual actions.

When,

$(1, \ldots, n)$ are representing the number of each phase,

PEC $(1 \ldots n)$ is the primary energy consumption of the building during each stage,

$\mathrm{d}(1 \ldots \mathrm{n})$ is the duration of each phase,

$\tau$ is the calculation period.

To calculate the global cost of the building's progressive renovation, a process that is defined in $\mathrm{EN}$ 15459 should be used while a different method should be used to calculate present value. The formulation to calculate the net present value factor to implement in the maintenance cost and each phase's cost calculation is as follows: (Eq. 2)

$P v(e, n)=\left(1-(1+R I / 100)^{\wedge}(-n)\right) /(R I / 100) * R d(i)$

When $\operatorname{Rd}(i)$ is the discount rate of related year and " $n$ " is the duration of the phase and RI is the real interest rate.

\section{Results and Discussion}

The result of the existing building simulations made by the EnergyPlus software was confirmed by the TÜBITAK supported study [10]. It shows that most of $\mathrm{PEC}$ is belonged to cooling. Afterward cooling that is account for $44 \%$ of total $139.25 \mathrm{kWh} / \mathrm{m}^{2}$.a PEC, illumination and pumps and fans with $23 \%$ and $22 \%$ are located, respectively. The heating system consumes only $4 \%$ of the total primary energy per year. Moreover, DHW constitutes only $7 \%$ of the PEC. (Fig. 3).

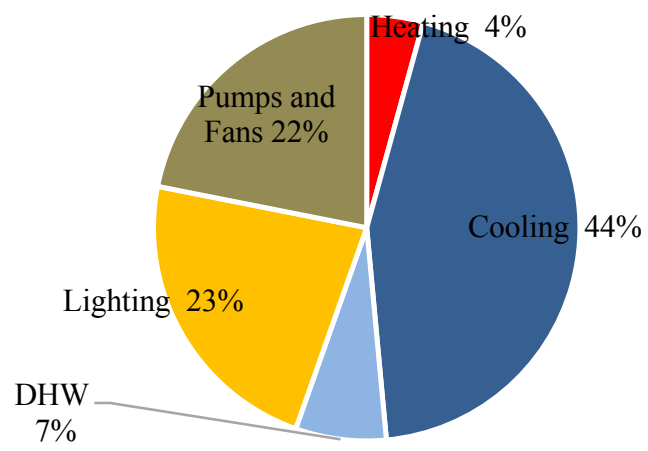

Fig. 3. PEC of the existing reference building.
The current building has a global cost of approximately $549 \mathrm{TL} / \mathrm{m}^{2}$. Changing of the existing noncondensing boilers to a central condensing boiler (S18) with a $111 \mathrm{kWh} / \mathrm{m}^{2} \mathrm{PEC}$ and global cost of $470 \mathrm{TL} / \mathrm{m}^{2}$ of the global cost is positioned at the bottommost point of the Global Cost (GC) vs PEC chart. Nine measures located above the existing building level should be excluded from additional analysis. Thus, the wall and all opaque system changes (S1-S4), shading system installations (S12-S13), solar collector implementation (S15), radiator system replacement with the heated floor (S16), in common with the air conditioner upgrade to a high COP (S21) are actions which are left out of subsequent analyses. Improvement of the glass system (S7-S11) reduces the global cost amount and the PEC of the present case. The sixth and seventh level glass renewal (S10-S11) have higher global cost compared to S9, so they cannot lead to a lower point in the GC against the PEC chart and should be excluded from additional analysis. Thus, the amount of necessary simulations is considerably deducted (Figure 4).

Rest of the measures are merged to consistue the renovation packages. To decrease the quantity of simulations, initially, combinations of the architectural and HVAC systems are recognised and analysed. As indicated before, in the current case, the architectural enhancement actions should be limited to glazing system alterations solely. From architectural and HVAC combined measures, six situations are economically reasonable combined measures (ERCMs). The features of the ERCMs scenarios are mentioned in Table 3. Overall, when the glazing system amendments except first and second level combined with central condensing boiler replacement include or exclude the first level of cooling system upgrade, the renovation measures are ERCMs. Furthermore, ERCMs can diminish GC by around $25 \%$ and PEC by nearby $42 \%$ (Table 3 ). 


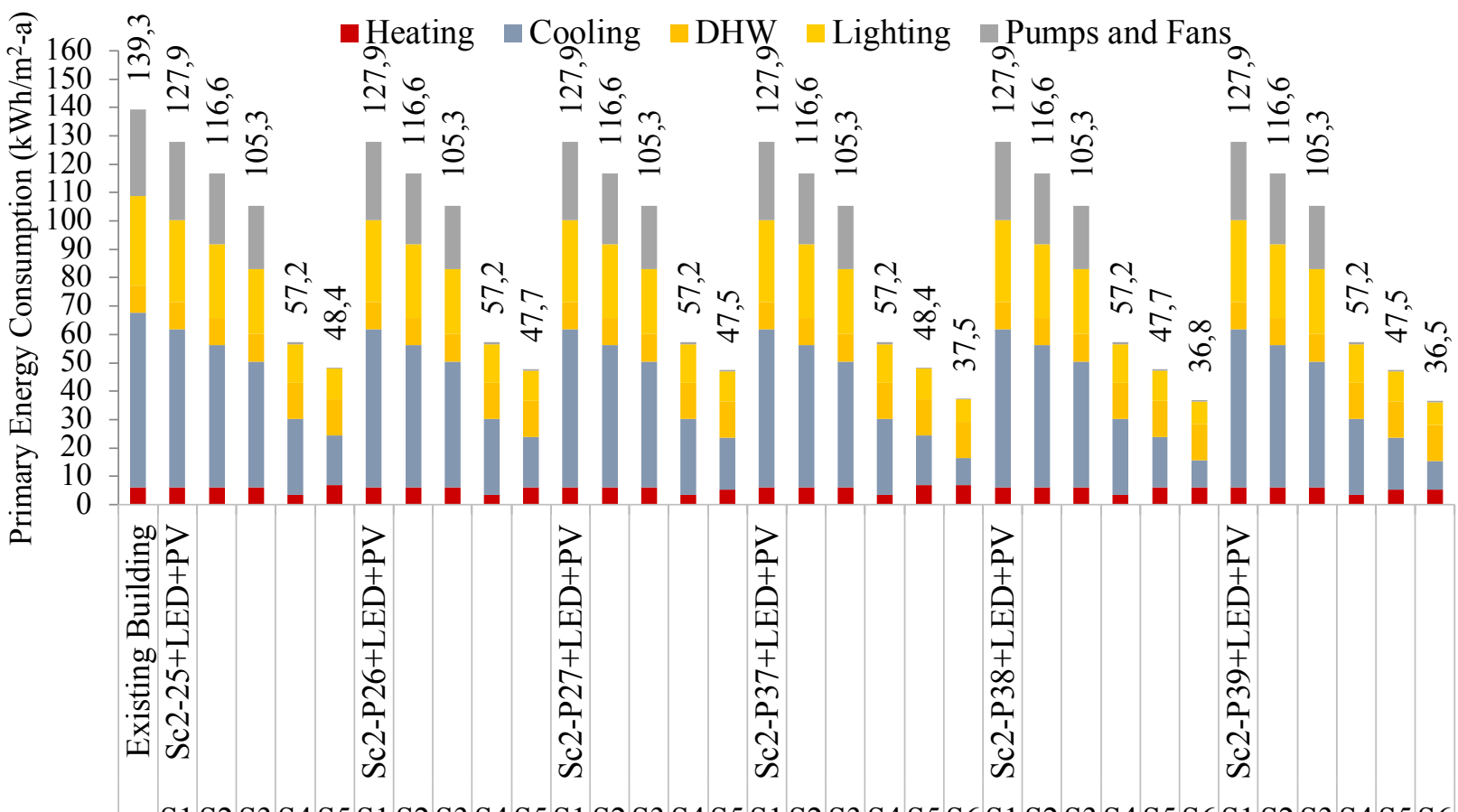

Fig. 5. PEC of each step with the second scenario application.

Table 3. Energy efficiency measures constitute the ERCMs.

\begin{tabular}{|l|l|l|}
\hline Acr. & $\begin{array}{l}\text { Energy Efficient } \\
\text { Measures } \\
\text { (Architecture) }\end{array}$ & $\begin{array}{l}\text { Energy Efficient Measure } \\
\text { (HVAC System) }\end{array}$ \\
\hline P25 & $3^{\text {rd }}$ Glazing (S7) & Condensing Central Boiler (S18) \\
\hline P26 & $4^{\text {th }}$ Glazing (S8) & Condensing Central Boiler (S18) \\
\hline P27 & $5^{\text {th }}$ Glazing (S9) & Condensing Central Boiler (S18) \\
\hline P37 & $3^{\text {th } \text { Glazing (S7) }}$ & $\begin{array}{l}\text { Condensing Central Boiler + Coil } \\
\text { COP }=3.5(\text { S18+S20) }\end{array}$ \\
\hline P38 & $4^{\text {th }}$ Glazing (S8) & $\begin{array}{l}\text { Condensing Central Boiler + Coil } \\
\text { COP }=3.5(\text { S18+S20) }\end{array}$ \\
\hline P39 & $5^{\text {th }}$ Glazing (S9) & $\begin{array}{l}\text { Condensing Central Boiler + Coil } \\
\text { COP }=3.5(S 18+S 20)\end{array}$ \\
\hline
\end{tabular}

Subsequently, lighting system enhancements are entegrated to the ERCMs and the PV system are then added to the combinations. Same analyses are carried out for the aforementioned combined measures, and the primary energy consumption graph is plotted against the global cost required for these operations. By changing the lighting system and applying the PV system to ERCMS, it is probable to get a global cost of approximately $375 \mathrm{TL} / \mathrm{m}^{2}$ and an average of 42.5 $\mathrm{kWh} / \mathrm{m}^{2}$ PEC. Alike to the earlier cases, these arrangements are placed at the bottom point of the graph, hence, they are cost-optimal actions. They can deliver in excess of $32 \%$ of primary energy and global cost savings for case studies.

The cost of initial investment and the cost per apartment are shown in Table 4. As can be seen, in every case, the contribution of each owner is more than the reasonable price. Therefore, they need to be analysed in order to perform step-by-step revisions. All scenarios have a repayment period of fewer than ten years.
Table 4. Cost per flat and payback time of the cost-optimal

\begin{tabular}{|c|c|c|c|}
\hline Opt. Scenario & $\begin{array}{c}\text { Overall } \\
\text { Initial } \\
\text { Investment } \\
\text { Cost (TL) }\end{array}$ & $\begin{array}{c}\text { Budget per } \\
\text { Flat (TL) }\end{array}$ & $\begin{array}{c}\text { Payback } \\
\text { Period } \\
\text { (Year) }\end{array}$ \\
\hline P25+LED+PV & $131,355.91$ & $13,135.59$ & 9.73 \\
\hline P26+LED+PV & $132,903.79$ & $13,290.38$ & 9.80 \\
\hline P27+LED+PV & $133,083.78$ & $13,308.38$ & 9.80 \\
\hline P37+LED+PV & $95,268.51$ & $9,526.85$ & 7.89 \\
\hline P38+LED+PV & $96,816.39$ & $9,681.64$ & 7.98 \\
\hline P39+LED+PV & $96,996.38$ & $9,699.64$ & 8.00 \\
\hline
\end{tabular}

The developments without cooling system improvements (P25+LED+PV, P26+LED+PV, and P27+LED+PV) have five stages (Table 5) while the rest include six phases. One-year postponements should apply to heating and cooling systems' improvements. PEC in each step of the second gradual retrofit scenario is presented in Figure 5.

There is a slight alteration between GC vs PEC of the specified two step-by-step scenarios. Overall, all arrangements have about $52 \mathrm{kWh} / \mathrm{m}^{2}$ average PEC and 385-395 TL $/ \mathrm{m}^{2} \mathrm{GC}$. The position of related situations in the GC vs PEC graph is indicating that compared with the cost-optimal renovation scenarios, step-by-step scenarios lead to as low as $7 \%$ increase in GC throughout the calculation period and around $24 \%$ raise in PEC. Compare with the GC and PEC saving of stepby-step scenarios that are $30 \%$ and $63 \%$ respectively. Thus, the negative points are negligible (Fig. 6). 


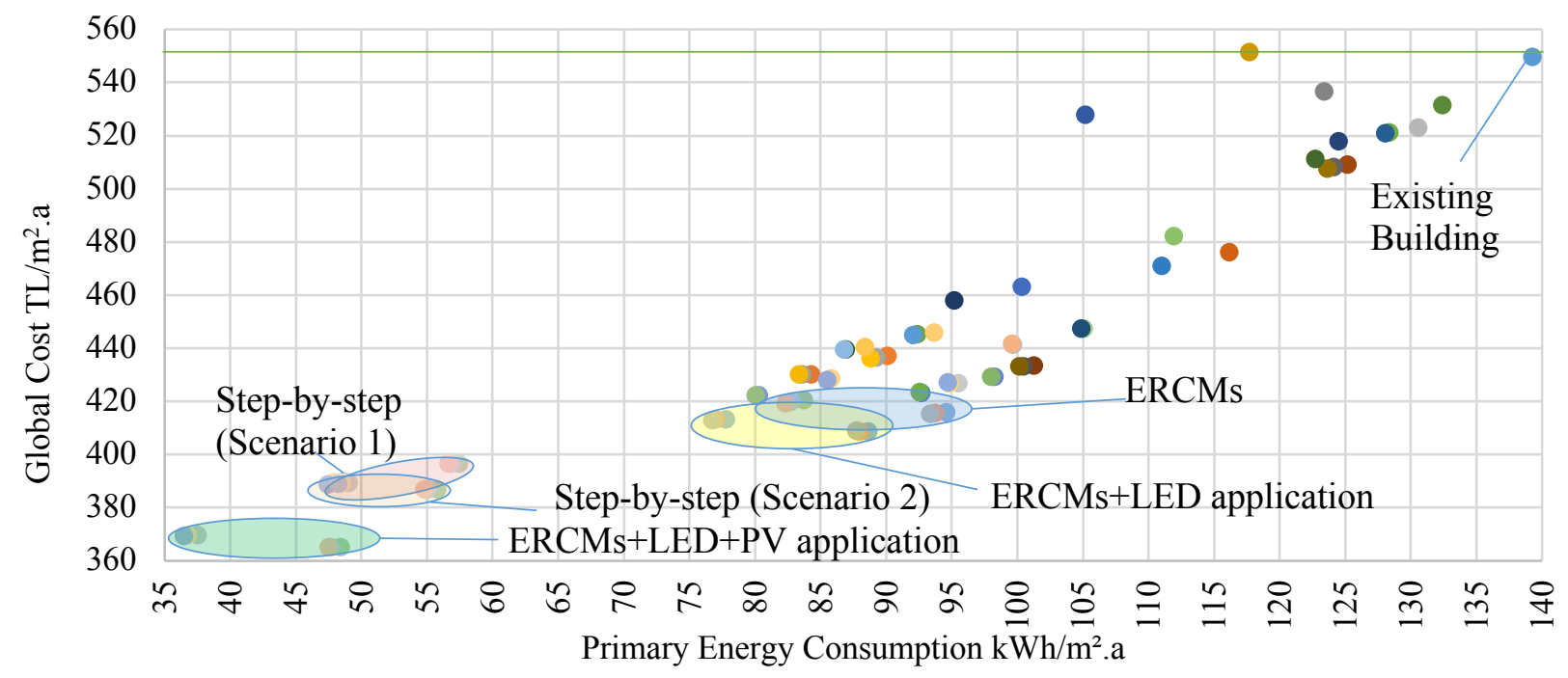

Fig. 6. The global cost vs primary energy consumption graph for the whole process.

Table 5. Definition of five phases for step-by-step scenarios.

\begin{tabular}{|c|c|c|c|c|c|c|c|}
\hline $\begin{array}{l}\frac{n}{0} \\
\frac{\pi}{2} \\
? \\
?\end{array}$ & 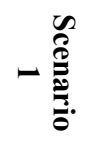 & ڤ્ఝ & 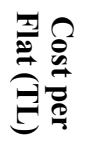 & $\begin{array}{l}\frac{n}{8} \\
\frac{\pi}{2} \\
?\end{array}$ & 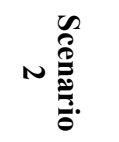 & $\begin{array}{l}\dddot{\AA} \\
ٍ\end{array}$ & 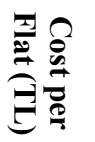 \\
\hline 1 & $\begin{array}{c}\text { Glazing } \\
\text { and } \\
\text { lighting }\end{array}$ & 0 & $\begin{array}{c}1620- \\
1790\end{array}$ & 1 & $1 / 3 \mathrm{PV}$ & 0 & 1817.2 \\
\hline 2 & Heating & 2 & 2456.5 & 2 & $1 / 3 \mathrm{PV}$ & 1 & 1817.2 \\
\hline 3 & $1 / 3 \mathrm{PV}$ & 3 & 1817.2 & 3 & $1 / 3 \mathrm{PV}$ & 2 & 1817.2 \\
\hline 4 & $1 / 3 \mathrm{PV}$ & 4 & 1817.2 & 4 & Heating & 4 & 2456.5 \\
\hline 5 & 1/3 PV & 5 & 1817.2 & 5 & $\begin{array}{l}\text { Glazing } \\
\text { and } \\
\text { lighting }\end{array}$ & 5 & $\begin{array}{c}1620- \\
1790\end{array}$ \\
\hline
\end{tabular}

The same approach is applied to a building with the same geometry, mechanical and lighting system but different architectural components properties in two other city in Turkey located in different climatical regions. The differentiation of the architectural component was due to variation in the requirement of TS-825 standard for each of these cities. The results are indicating that however the amount of primary energy and global cost savings are differernt in these cases, the behavior of step-by-step retrofits are not varied. In all of these three cases, gradual application of retrofit measures are not reducing the saving and benefits remarkably. In the cold climate, the global cost saving reduction is as low as $0.47 \%$ and in the temperate climate, it is $3.33 \%$. Primary Energy saving reductions also are also lower than first case and are $4.86 \%$ and $3.17 \%$ for Erzurum and Istanbul respectively. (Fig. 7)

\section{Summary}

The current situation in improving the energy performance of buildings is far from the EU targets in both EU member states and related countries; because the regeneration rates are still meagre with about half of the goal. One of the main obstacles to deep renovations of existing buildings is the shortcomings in financial resources. As an EU candidate member, Turkey, much more action and there are no incentives for improving the energy performance of buildings. The most common renewal is the wall-backed insulation application

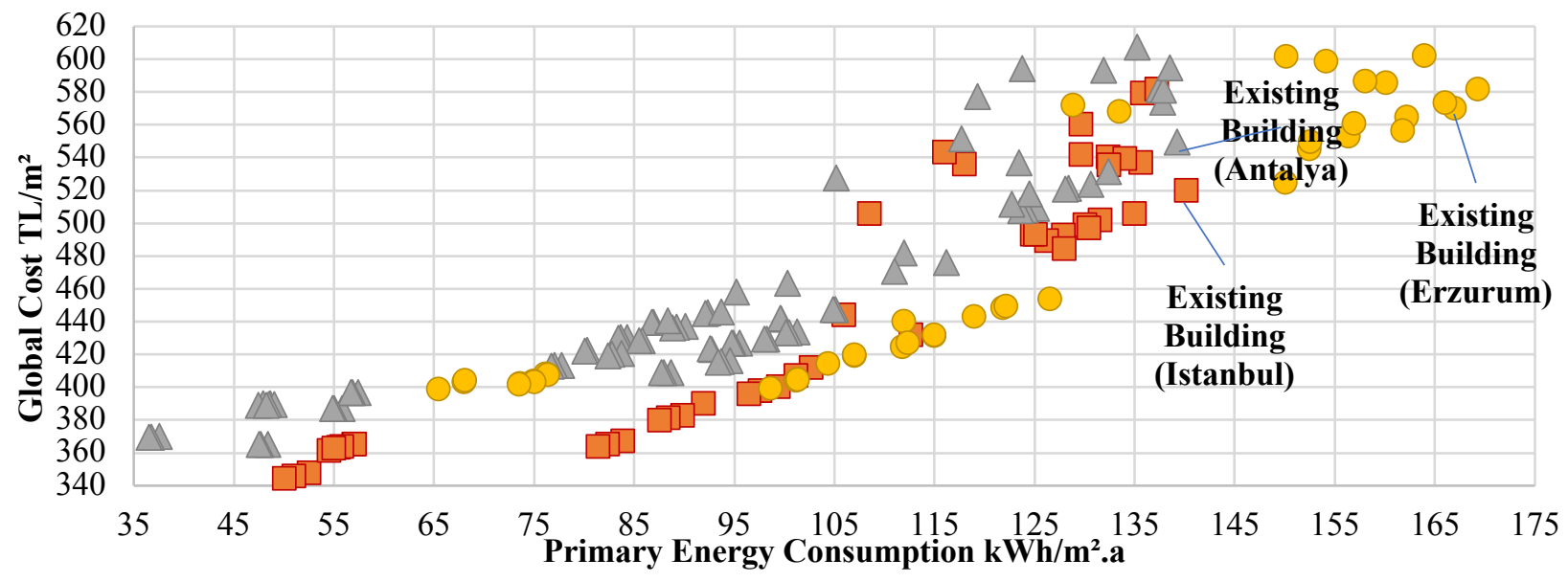

Fig. 7. The global cost vs primary energy consumption graph for the whole process applied to three different cities. 
because it is the only incentive option. Insulation enhancements can only diminish a small portion of energy use, and are even detrimental to buildings with high internal gains, as they can sometimes increase cooling energy consumption. This work attempts to compete by encouraging owners to participate in their actions as financiers. This study aims to bring an approach to expand the applicability of retrofit activities. In this means, the research established an exemplary process with the global cost calculation method for the progress of national cost optimisation methodologies that take into account local market situations. Also, an immediate and cost-effective adaptation of the calculation method for the renewal step, which is defined as a national reference building located in Turkey's warm-humid regions has been analysed in a residential row building.

The results of the study show that it is possible to achieve a $33 \%$ global cost and $75 \%$ primary energy saving by even non-advanced technology development, in the housing sector of Turkey. These scenarios can cut $\mathrm{CO}_{2}$ emissions by in excess of $70 \%$. All of these renewals have a repayment period of fewer than ten years. Such a transaction has an initial investment cost of at least 9527 TL per apartment. This cost, if implemented immediately, is a tremendous amount compared to the annual income of households. The reception requires enormous financial support, so it is unacceptable for most of the Turkish property owners. Therefore, it is essential to use multi-step or step-by-step scenarios to make them applicable and applicable. With such situations, it is probable to decrease the initial investment cost to approximately TL 2310 per apartment for each step. Based on national data of regular household income, it is a rational amount of annual payments. Hence, the primary energy and global cost savings will be almost $65 \%$ and $30 \%$ respectively. The decrease in savings can be neglected compared to the benefits arising from the increase in the annual renewal rate at the national level. Thus, the approach has a potential to apply in a large building number to achive a high benefit in long-term.

To obtain a definite result, we need to support the analysis with further studies including different building types. Also, developed goals can be applied by doing more research. For instance, a comparable approach can be applied to adaptations to nearly zero-energy building level rather than cost-optimal level. The common renovation measures can be inadequate to achieve a higher energy performance, thus deep improvements in the energy systems of the buildings will be required to reduce energy consumption sufficiently. Such renewal measures are often costly but should be explored through step-by-step renewal to be satisfactory for owners.

\section{References}

1. M. Economidou, Europe's Buildings under the Microscope: A country-by-country review of the energy performance of buildings, Buildings Performance Institute Europe (BPIE) (2011)
2. J. O. Lewis, S. Ni Hogain, A. Borghi, Building energy efficiency in European cities, URBACT, Saint-Denis, France, (2013)

3. G. Desogus, L. Di Pilla, S. Mura, G.L. Pisano, R. Ricciu, Economic efficiency of social housing thermal upgrade in Mediterranean climate, Energy and Buildings 57, pp. 354-360 (2013).

4. F. Liu, A. S. Meyer, J.F. Hogan, Mainstreaming Building Energy Efficiency Codes in Developing Countries, The World Bank, Washington, U.S., (2010)

5. EU Commission, Directive 2010/31/EU on the energy performance of buildings (recast). Official journal of the European Union, 153 (2010) 13-35.

6. EU Commission, Directive 2012/27/EU on energy efficiency, Official Journal of the European Union, 315(2012) pp. 1-56.

7. EU Commission, Financial support for energy efficiency in buildings, Brussels, Belgium, 2013.

8. EU Commission, Directive (EU) 2018/ of the European Parliament and of the Council of 30 May 2018 amending Directive 2010/31/EU on the energy performance of buildings and Directive 2012/27/EU on energy efficiency, Official Journal of the European Union, no. L 156, 2018.

9. EU Commission, Directive (Eu) 2018/844 of the European Parliament and of the Council of 30 May 2018, 156 (2018) pp. 75-91

10. Turkish Ministry of Public Works and Government, Building Energy Performance Regulation, Turkish Official Gazette, 27075, 5 December 2008.

11. A.Z. Yilmaz, T. Ashrafian, N. Ganic, G. Gali, A. Akguc, Determination of Turkish Reference Residential Buildings and National Method for Defining Cost Optimum Energy Efficiency Level of Buildings (Project no:113M596), TUBITAK, Ankara, Turkey, 2015.

12. T. Ashrafian, A. Z. Yilmaz, S. P. Corgnati, and N. Moazzen, Methodology to define cost-optimal level of architectural measures for energy efficient retrofits of existing detached residential buildings in Turkey, Energy and Buildings, vol. 120, pp. 58-77, May 2016.

13. European Committee for Standardization (CEN), EN 15459 Energy performance of buildings Economic evaluation procedure for energy systems in buildings, Brussels, Belgium, 2007.

14. European Committee for Standardization (CEN), EN 13465: Ventilation for Buildings - Calculation Methods for the Determination of Air Flow Rates in Dwellings, Brussels, Belgium, 2004.

15. Turkish Standardization Ins., TS825: Thermal insulation requirements, Ankara, Turkey, 2013. 